\title{
Habitação Evolutiva Reflexões sobre Alguns Casos: Possibilidades
}

Paulo Sérgio de Sousa e Silva

Resumo

O texto refere-se à habitação evolutiva, destinada à população de baixa renda, comparando empreendimentos promovidos pela Prefeitura de São Paulo, através de duas formas diversas de produçăo do núcleo inicial - embrião - uma delas, a ajuda mútua, com participaçăo intensa da população interessada e a outra baseada no trabalho exclusivo de empreiteiras especializadas.

This paper refers to low cost housing, promoted by São Paulo municipal bodies, based in one family core-houses. Two different systems are analysed, one of them based in mutual help, with community participation, the other based in professional teams.
Arquiteto e Mestre pela FAUUSP, 1989.

Extralda da Dissertação de Mestrado "Moradia evolutiva: do Promorar Penha". jan. 1989.

Orientador: Carlos A. C. Lemos. 


\section{Da Abrangência e dos Objetivos do Trabalho}

O "problema habitacional" vem impondo um leque amplo de "soluçōes", ou formas de intervenção por parte dos setores públicos pertinentes, formas essas correspondentes a um relativo consenso no meio técnico, embora nem todas ainda plenamente institucionalizadas, tendo-se em vista os setores populacionais de baixa renda. Refiro-me à urbanização de favelas, ả melhoria de loteamentos precários, ao apoio ả autoconstrução, à produção de lotes urbanizados, à produção de unidades acabadas - casas e apartamentos - e à produção de unidades evolutivas. Seriam formas complementares de atuação por parte da administração pública, sua eleição devendo depender, basicamente, de todo um conjunto de fatores peculiares a cada situação, como a disponibilidade de terreno, os requisitos das linhas de financiamento que se pretenda acionar, a pressão exercida por movimentos populares, etc.

Uma das modalidades acima referidas, a habitação evolutiva consiste em unidades residenciais unifamiliares constituldas de um núcleo inicial, despojado de acabamentos e de área exlgua, suscetlivel, por definição, ả melhoria e à ampliação por iniciativa dos proprietários, já instalados nas edificações. Considerada a polftica habitacional vigente em São Paulo de alguns anos para cá, a habitação evolutiva, quando resultante de empreendimentos a cargo dos orgāos públicos pertinentes, vem assumindo duas formas diversas, no que diz respeito ao processo de produção do núcleo inicial, também conhecido como embriāo. Uma delas é a ajuda-mútua, ou mutirão, que pressupōe a participação predominante da mão-de-obra da população interessada. A outra, mais freqüente e menos polêmica, corresponde à produção baseada em trabalhos exclusivos de empreiteiras especializadas.

O presente texto diz respeito a empreendimentos recentes, promovidos pela Prefeitura paulistana, no åmbito das duas modalidades de produção acima referidas, ou seja, os conjuntos habitacionais implantados através do Programa Promorar, entāo vigente junto ao BNH, entre 1979 e 1983 e os setores que integram o Projeto Mutirão N. Sra. da Penha, realizado entre 1985 e 1987. Os conjuntos Promorar foram edificados por empreiteiras, sem a interferência dos futuros usuários, enquanto que o N. Sra. da Penha baseou-se no processo de ajuda-mútua, tendo sido contratada de terceiros tão somente a execução da terraplenagem, da fundação e da primeira fiada da alvenaria das habitaçōes. Uma análise comparativa das áreas Promorar e dos setores do Penha, como se apresentam hoje, revela alguns aspectos de particular interesse em empreendimentos dessa natureza. É o que faremos em seguida.

As áreas Promorar e os setores do Penha não constituem casos isolados de empreendimentos dessa natureza no municlpio, outros exemplos, tão ou mais significativos, vêm ocorrendo e merecem atenção por parte daqueles que se interessam pela questão. Foram adotadas como referência para as reflexōes abaixo desenvolvidas por terem constituldo o universo abrangido pela Dissertação de Mestrado que venho apresentar junto à Faculdade de Arquitetura e Urbanismo da Universidade de São Paulo, com o tftulo "Morada Evolutiva: do Promorar Penha", e devido à minha participaçåo na sua implantação: no Penha, como coordenador do empreendimento junto à Secretaria de Habitaçăo do Município e autor dos projetos de arquitetura e urbanismo pertinentes e no Promorar, como responsável - durante parte da vigência do programa - pela equipe da EMURB - Empresa Municipal de Urbanização, encarregada dos projetos dos assentamentos em questāo. Em decorrência desse envolvimento, as consideraçōes que se seguem refletem uma visão pessoal do problema. Seu objetivo é contribuir para a memória da produção e consumo desses conjuntos e aduzir alguns subsidios para projetos de natureza semelhante, sem que haja, portanto a pretensāo de abarcar toda a complexidade do assunto.

\section{Do Processo de Adaptação dos Assentamentos}

Como era de se prever, em se tratando de habitação evolutiva, uma vez edificados e ocupados, tanto os conjuntos Promorar quanto os setores que integram o Penha, vêm 
passando por um processo relativamente intenso de adaptação, por parte de seus moradores. Em que pesem diferença nas "idades" desses assentamentos, na sua escala e em outros condicionantes, algumas caracteristicas peculiares a esse processo já podem ser detectadas nas diversas áreas, como subsídio para um conhecimento mais objetivo do-problema e para a elaboração de novos projetos.

Um aspecto logo se impōe, nas ampliaçōes efetuadas nas unidades residenciais das áreas Promorar: o uso quase generalizado de lajes de cobertura, freqüentemente com tripla função: cobertura, terraço/depठsito e piso de um futuro pavimento superior, evidenciado pelos inexoráveis ferros de espera. Há indlicios de que tal opção implica em problemas de umidade e falta de isolamento térmico no interior das habitaçōes. Confirmada essa hipótese concluirlamos que o morador prefere "bancar" esses inconvenientes, em troca de maior segurança, de espaço (particularmente valioso em lotes de apenas $75 \mathrm{~m}^{2}$ ) e da possibilidade de ampliar futuramente a área construlda. No N. Sra. da Penha tal solução vem sendo adotada nas ampliaçōes "horizontais" (no térreo). Nas ampliaçöes "verticais" tem sido, entretanto, usada cobertura de telhas onduladas de cimento-amianto eventualmente com laje horizontal de forro, utilizando-se o mesmo material (telhas e madeiramento) usado no núcleo inicial, o que explica o porquê da opçăo por esse sistema. Ou seja, exceto em situaçōes excepcionais, como a que ocorreu no Penha, fica evidente a preferência, por parte das populaçōes interessadas, quanto a cobertura de laje. As unidades residenciais deverão ser projetadas com base nessa premissa, devendo-se prever, também, possibilidades de ampliação na vertical e de utilização da laje para terraço e outros usos pertinentes.

Outro fator que salta aos olhos numa análise das áreas Promorar - e que no Penha apenas se esboça - é a freqũente "ocupação abusiva" dos lotes residenciais. Ou seja, ampliaçōes ocupando excessivamente os terrenos (às vezes $100 \%$ da área), comprometendo, irremediavelmente, as condiçōes de conforto e higiene das habitaçōes. Tal problema denota a falta de orientação aos usuários e de fiscalização, por parte dos órgãos responsáveis. É provável que decorra, também e possilvelmente mais, das tipologias casa/lote adotadas, as quais não estariam possibilitando, particularmente em algumas áreas Promorar, alternativas de ampliação adequadas às reais necessidades e recursos técnicos/econômicos dos moradores. O estudo de novas soluçōes deverá contemplar cuidadosamente esse aspecto, sendo necessário que se conheçam melhor os fatores de ordem cultural que explicam determinadas formas de arranjo e uso de espaço residencial. $O$ levantamento $\mathrm{e} a$ análise permanentes das soluçōes que vêm sendo adotadas pelos usuários será, nesse sentido, de grande valia. A questão orientação/fiscalização é de natureza administrativa e parece não ser de solução viável a curto prazo. Deverá, nesse sentido, ser entendida como um dado, ou seja, um condicionante a mais, a ser atendido no projeto de habitaçőes evolutivas.

Uma terceira caracterlstica, freqüente no Promorar e previsivel no Penha, é a instalação, em parcelas das unidades residenciais, de pequenos estabelecimentos de comércio, serviços e até culto religioso, contrariando determinação dos órgãos habitacionais, que insistem na funçăo exclusivamente residencial dos conjuntos, mas que "fecham os olhos $^{n}$, diante dos fatos. Pode-se, por outro lado, observar uma tendência de localização desses estabelecimentos em pontos estratégicos, considerada a função que exercem (esquinas para o comércio, por exemplo) e de aglutinaçăo, ao longo das vias de maior acessibilidade e movimento, esboçando futuros eixos de uso misto, absolutamente não previstos em projeto. Aglutinam-se, também, unidades residenciais mais cuidadas no acabamento e nas ampliaçōes, reproduzindo, na escala de cada conjunto, a estratificação social que ocorre no conjunto da cidade. Tendências dessa natureza, já evidentes em alguns dos assentamentos em questão, deverăo ser objeto de estudo, tendo-se em vista a concepção de novos conjuntos, os quais deverão se ordenar através de estruturas mais abertas, que possam incorporar, sem se descaracterizarem, essa dinåmica pouco previsível, de adaptação do espaço coletivo.

A compreensão desse processo de modificação dos conjuntos analisados, por parte dos usuários, individuos e grupos sociais al instalados - a "população-meta" dos projetos em questão - pressupōe o conhecimento de alguns fatores precedentes, que res- 


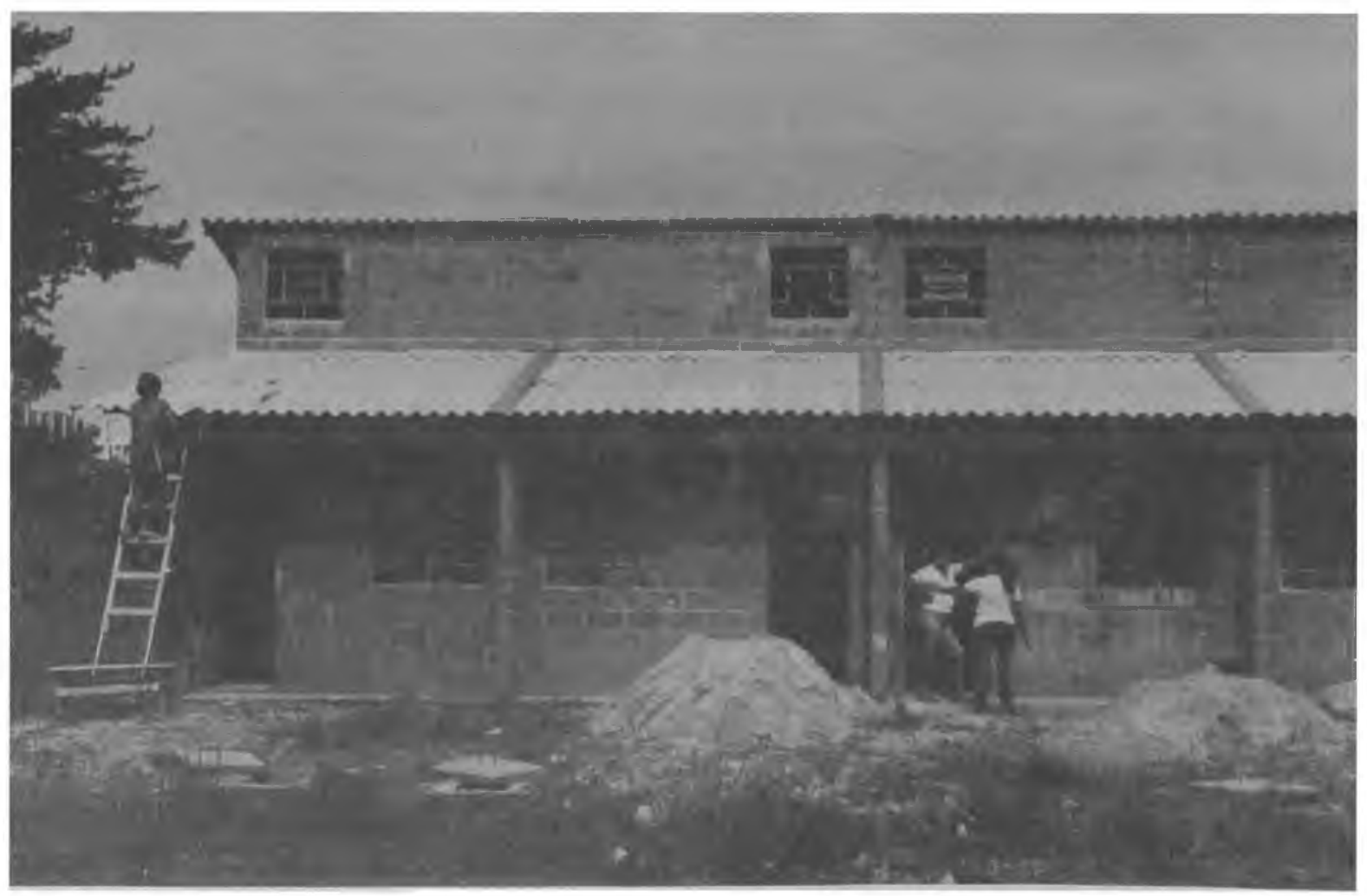

Pos - R. Prog. Pó-Grad. Arquit. Urb. FAUUSP, 
pondem pela conformação desses cenários onde irão atuar os moradores, seus vizinhos, os órgãos públicos competentes e demais atores, os quais cumpre identificar e caracterizar. Entre esses condicionantes estão a participação do grupo interessado em todas as etapas do empreendimento, o processo de produçăo das moradias e a concepção - projeto - dos assentamentos e de seus componentes.

\section{Da Participação da População Interessada}

O Promorar e o Penha pouco diferem em termos quantitativos (área edificada e área dos lotes) ou nas especificaçőes básicas das unidades-embrião (padrão de acabamento, número e natureza dos compartimentos, padrōes da infra-estrutura, etc.). A diferença é sensivel, entretanto, no que diz respeito à questăo da participaçăo da população interessada, em todo o processo de implantação do conjunto, passando pela concepção urbanistica e arquitetônica. No Promorar essa participação era praticamente inexistente, sendo incipiente o contato entre os futuros moradores e os órgãos responsáveis e, conseqüentemente, as equipes de projeto. Já no Penha o processo foi de outra natureza: se o conjunto existe é devido, antes de mais nada, à capacidade de organização, à clareza de objetivos e à luta constante, por parte do grupo interessado, tendo cabido à administraçāo pública viabilizar o projeto, mobilizando os recursos e instrumentos institucionais disponiveis.

Essa capacidade de mobilizaçăo dos integrantes do Penha vem se mantendo, mesmo após atingido o objetivo inicial, uma vez que o grupo hoje associa com os projetos habitacionais vizinhos da Vila Nova Cachoeirinha (mutirão) e Boi Malhado (relocação de favela), tendo em vista a consecução de objetivos comuns, que extrapolam a casa própria. Há que se acompanhar esse processo e verificar se esse fator contribuirá para a manutenção dessa populaçāo no assentamento, evitando reeditar o que vem ocorrendo nas áreas Promorar, onde o exôdo já se mostra significativo: segundo fontes da Cohab, em apenas 8 anos de Promorar, cerca de $30 \%$ dos moradores não são mais os originais, chegando essa relação a $50 \%$ no conjunto Vila Maria.

Bandeira polftica ou jargão técnico, a participação vem sendo considerada, cada vez mais, um dos requisitos básicos do próprio exercício da cidadania. Será, cada vez mais, um dos condicionantes fundamentais na atuação de todos os setores que intervêm na produção do espaço habitável. Esse fator irá condicionar, como de certa forma ocorreu no Penha, a atuação futura dos projetistas, dal a importåncia que assume o balisamento e a avaliação de projetos dessa natureza.

\section{Da Produção dos Assentamentos}

A experiência do Promorar colocou em evidência um aspecto fundamental no que se refere à produção dos assentamentos em questão: trata-se da qualidade do produto habitacional, aqui entendida, especificamente, enquanto fidelidade ao estabelecido em projeto. A adoção, na maioria dos conjuntos, de materiais e sistemas construtivos não suficientemente testados, e a ausencia de um controle de qualidade por parte dos orgãos responsáveis, atenderam mais à conveniência de algumas empreiteiras e ao cumprimento de prazos polfticos, do que a objetivos claramente estabelecidos, e que inclulssem padrōes minimos de durabilidade, segurança, conforto e outros requisitos usuais. Na prática repassou-se para o usuário indefeso o ônus de experiências mal conduzidas. No Penha tais problemas não ocorreram, apesar da utilização de mão-deobra pouco habilitada, inerente ao processo de ajuda-mútua. Uma das conclusões que esse cotejo Promorar-Penha sugere, diz respeito, mais uma vez, ao papel decisivo do futuro usuário, como controlador da qualidade do produto, o que poderia ser exercido, por exemplo, através de profissionais ou entidades isentos, os quais se reportariam diretamente à comunidade interessada. Medidas dessa natureza não eximem, entretanto, a administração pública e demais entidades intervenientes, quanto à sua responsabilidade em todo o processo de produção da moradia popular. 


\section{Da Concepção dos Assentamentos}

A apreciação do Promorar e do Penha passa, finalmente, pela concepção dos conjuntos, no que se refere à ordenação espacial das edificaçōes e dos assentamentos, vale dizer, em termos de arquitetura e desenho urbano. Alguns aspectos relativos a essa questão já foram mencionados ou estão implicitos nos itens anteriores, outros cabem ser enfatizados, como, por exemplo, as unidades residenciais do Promorar, cujo projeto nem sempre atendia às condiçōes de higiene e conforto requeridas. Dentre as tipologias adotadas, poucas possibilitavam, como já referido, soluçōes adequadas quanto à futura ampliação, vetando-se, inclusive, a ampliação sobre os embriōes, medida constrangedora ao se considerar a exigüidade dos lotes. Já no Penha, a tipologia casa/lote era diversa, baseada em lotes de frente menor $(3,60 \mathrm{~m})$ e casas geminadas em ambos os lados, não apresentando a maioria dos problemas detectados no Promorar, possibilitando ampliaçōes na vertical (poucas opçōes), embora resultando pouco propicia a ampliações na horizontal. Do que foi exposto pode-se concluir pela necessidade de se estudarem novas hipóteses de unidade residencial que comportem, entre outros aspectos, várias alternativas de ampliação bem resolvidas, tanto na horizontal quanto na vertical, com até 3 pavimentos, admitindo-se a eventual superposição - que pode ser constatada nas áreas analisadas - de domichios, com entradas independentes.

No que se refere à ordenação espacial dos conjuntos, a adoção de soluçōes baseadas em movimento de terra maciço, particularmente em algumas áreas Promorar, resultou, entre outros inconvenientes, em taludes de grande porte, que na prática vêm acarretando uma série de problemas, seja por constituirem barreiras que segregam setores dos conjuntos ou os assentamentos de sua vizinhança, seja por se transformarem em depósitos de lixo, uma vez que são "terras de ninguém" Essa constatação sugere revisăo radical nos critérios de "modelagem" do terreno: redução do volume de terraplenagem ao minimo possivel, "privatizaçăo dos taludes" (localizando-os dentro dos lotes) e, de maneira geral, um traçado geomórfico, ou seja, que implique numa verdadeira reconciliação com os dados do terreno. Alguns bairros implantados pela Cia. City em São Paulo, particularmente o Pacaembú, constituem, sob esse aspecto, acervo importante, digno de ser avaliado e incorporado ao repertório de soluções e critérios adotados em projetos dessa natureza.

Numa escala "micro", ou seja, na que abarca o espaço contlguo às habitaçōes, muito pouco tem sido feito, exceto algumas tentativas no Promorar ("pontos de encontro" associados a patamares de escadarias), aparentemente bem sucedidas, e no Penha, como algumas "pracinhas" associadas a retornos do sistema viário, que requerem avaliação especffica. No entanto trata-se de um componente importante do desenho desses assentamentos, capaz de favorecer à socialização dos moradores.

De maneira geral caberia, por fim, aprofundarem-se os aspectos ligados à fundamentação teórica e ideológica dos projetos em questão. Há um costume de se relegar ao segundo plano essa preocupação, quando o tema é habitação popular. Fica o convite para que se inclua o problema no discurso conceituai. 